\title{
Nagging Pain
}

National Cancer Institute

\section{Source}

National Cancer Institute. Nagging Pain. NCI Thesaurus. Code C101165.

A sensation of discomfort or distress that is persistent and continuous. 